\title{
Bounce behavior of freshly nucleated biogenic secondary organic aerosol particles
}

\author{
A. Virtanen ${ }^{1}$, J. Kannosto ${ }^{1}$, H. Kuuluvainen ${ }^{1}$, A. Arffman $^{1}$, J. Joutsensaari ${ }^{2}$, E. Saukko ${ }^{1}$, L. Hao ${ }^{2}$, P. Yli-Pirilä ${ }^{3}$, \\ P. Tiitta ${ }^{2}$, J. K. Holopainen ${ }^{3}$, J. Keskinen ${ }^{1}$, D. R. Worsnop ${ }^{2,4,5}$, J. N. Smith ${ }^{2,6,7}$, and A. Laaksonen ${ }^{2,4}$ \\ ${ }^{1}$ Tampere University of Technology, Department of Physics, P.O. Box 692, 33101 Tampere, Finland \\ ${ }^{2}$ University of Eastern Finland, Department of Applied Physics, P.O. Box 1627, 70211 Kuopio, Finland \\ ${ }^{3}$ University of Eastern Finland, Department of Environmental Science, P.O. Box 1627, 70211 Kuopio, Finland \\ ${ }^{4}$ Finnish Meteorological Institute, P.O. Box 503, 00101 Helsinki, Finland \\ ${ }^{5}$ Aerodyne Research, Billerica, MA 08121-3976, USA \\ ${ }^{6}$ Finnish Meteorological Institute, P.O. Box 1627, Kuopio, Finland \\ ${ }^{7}$ National Center for Atmospheric Research, P.O. Box 3000, Boulder, CO 80307, USA
}

Received: 23 February 2011 - Published in Atmos. Chem. Phys. Discuss.: 21 March 2011

Revised: 12 August 2011 - Accepted: 23 August 2011 - Published: 26 August 2011

\begin{abstract}
The assessment of the climatic impacts and adverse health effects of atmospheric aerosol particles requires detailed information on particle properties. However, very limited information is available on the morphology and phase state of secondary organic aerosol (SOA) particles. The physical state of particles greatly affects particulatephase chemical reactions, and thus the growth rates of newly formed atmospheric aerosol. Thus verifying the physical phase state of SOA particles gives new and important insight into their formation, subsequent growth, and consequently potential atmospheric impacts. According to our recent study, biogenic SOA particles produced in laboratory chambers from the oxidation of real plant emissions as well as in ambient boreal forest atmospheres can exist in a solid phase in size range $>30 \mathrm{~nm}$. In this paper, we extend previously published results to diameters in the range of 17$30 \mathrm{~nm}$. The physical phase of the particles is studied by investigating particle bounce properties utilizing electrical low pressure impactor (ELPI). We also investigate the effect of estimates of particle density on the interpretation of our bounce observations. According to the results presented in this paper, particle bounce clearly decreases with decreasing particle size in sub $30 \mathrm{~nm}$ size range. The comparison measurements by ammonium sulphate and investigation of the particle impaction velocities strongly suggest that the de-
\end{abstract}

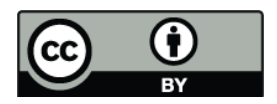

Correspondence to: A. Virtanen (annele.virtanen@tut.fi) creasing bounce is caused by the differences in composition and phase of large (diameters greater than $30 \mathrm{~nm}$ ) and smaller (diameters between 17 and $30 \mathrm{~nm}$ ) particles.

\section{Introduction}

Secondary aerosol formation via nucleation of precursor vapors and subsequent condensational growth has been reported to produce atmospheric aerosol in a variety of environments (e.g., Kulmala et al., 2004; Laaksonen et al., 2005). Numerous modelling studies (e.g., Spracklen et al., 2006) suggest that these particles are likely to have a significant impact on climate. The assessment of the climatic impacts and adverse health effects of atmospheric aerosol particles require detailed information on particle properties. Oxidation products of volatile organic compounds (VOC) emitted by sources such as vegetation participate in the formation and growth process of the newly formed atmospheric particles (Laaksonen et al., 2008, Kanakidou et al., 2005, Jimenez et al., 2009; Claeys et al., 2004). These are called secondary organic aerosols (SOA). Recent estimates on the importance of SOA formation show that it may be as significant as primary organic aerosol emissions, comprising about $60-70 \%$ of the organic aerosol mass on the global scale and regionally even higher (Hallquist et al., 2009, Kanakidou et al., 2005). Furthermore, substantial formation of biogenic SOA takes place over the boreal forest in northern Europe, indicating that the forest is a major source of climate-relevant aerosol particles

Published by Copernicus Publications on behalf of the European Geosciences Union. 
Table 1. Summary of plant chamber experiments. Values are determined at the beginning of trials (density during experiments \pm standard deviation).

\begin{tabular}{lllllllll}
\hline$\#$ & Experiment & $\mathrm{VOC}$ & $\mathrm{O}_{3}$ & $\mathrm{SO}_{2}$ & $\mathrm{TME}$ & $\mathrm{RH}$ & $T$ & density \\
\hline & & $(\mathrm{ppb})$ & $(\mathrm{ppb})$ & $(\mathrm{ppb})$ & $(\mathrm{ppb})$ & $(\%)$ & $\left({ }^{\circ} \mathrm{C}\right)$ & $\mathrm{g} \mathrm{cm}^{-3}$ \\
1 & Pine $+\mathrm{O}_{3}$ & 16.8 & 35 & - & - & 34 & 22 & $1.00 \pm 0.06$ \\
2 & Pine $+\mathrm{OH}+\mathrm{SO}_{2}$ & 107.6 & 35 & 22 & 35.2 & 31 & 22 & $1.10 \pm 0.07$ \\
\hline
\end{tabular}

(Tunved et al., 2006). SOA formation and properties are widely studied to clarify the role of SOA in radiative forcing and climate. In spite of their importance, the exact species and mechanisms that are responsible for the formation and growth of SOA is still not known. This is especially true for sub-30 nm diameter particles, for which the Kelvin effect predicts that a relatively small subset of available aerosol precursors participate in gas-particle partitioning due to their volatility.

It is well known that inorganic salts such as $\mathrm{NH}_{4}\left(\mathrm{SO}_{4}\right)_{2}$ and $\mathrm{NaCl}$ can be found in liquid droplets or solid crystals in the atmosphere depending on the surrounding humidity and temperature (e.g., Martin, 2000). However, very limited information is available on the morphology and phase state of SOA particles. According to our recent study, biogenic SOA particles produced in laboratory chambers from the oxidation of real plant emissions as well as in ambient boreal forest atmospheres can exist in a solid phase (Virtanen et al., 2010). In addition, the results of Cappa and Wilson (2011) indicate that the SOA particles formed through $\alpha$-pinene ozonolysis might be in a solid amorphous state rather than liquid. The physical state of particles greatly affects chemical reactions in the particles, and thus the growth rates of newly formed atmospheric aerosol. For highly viscous and solid particles, chemical reactions are typically surface-limited (i.e., heterogeneous reaction on particle surfaces). Zobrist et al. (2008) and others (Murray 2008; Mikhailkov et al., 2009) also suggested that the water uptake of the particles is diminished or even fully inhibited for highly viscous or glassy aerosols. In gas-to-particle partitioning models developed for SOA particles, it is generally assumed that particles are in liquid state (Pankow, 1994; Odum et al., 1996). Thus verifying the physical phase state of SOA particles gives new and important insight into their formation and growth process and essential information on their atmospheric impacts.

The physical phase of the particles can be studied by investigating particle bounce properties (Virtanen et al., 2010). When an aerosol particle collides with an impaction surface, one part of its kinetic energy is dissipated in the deformation process, and another part is converted elastically into kinetic energy of rebound. If the rebound energy exceeds the adhesion energy, the particle will bounce from the surface. Thus both the elastic properties and surface properties of particles affect their bounce probability (Rogers and Reed, 1984). Relative humidity (RH) also affects the bounce probability as RH influences the viscoelastic properties of hygroscopic aerosol particles (Stein et al., 1994). Generally, harder materials, larger particles or greater impact velocity will lead to a higher bounce probability, although the roughness of the collecting surface also plays a significant role (Dahneke, 1971, Chang et al., 1991). In our recent paper (Virtanen et al., 2010) we showed that biogenic SOA particles bounce in impactor stages, indicating that the particles are solid in their physical phase. Based on electron diffraction analysis and bounce measurements of liquid, crystalline and amorphous solid laboratory-generated aerosol, we concluded that biogenic SOA particles larger than $30 \mathrm{~nm}$ in diameter are amorphous solids. In this paper, we extend these results to diameters in the range of $17-30 \mathrm{~nm}$. Furthermore, we investigate the effect of estimates of particle density on the interpretation of our bounce observations.

\section{Methods}

\subsection{Chamber experiments}

The SOA experiments were performed at the Kuopio aerosol research chamber using living Scots pine trees as a natural source of VOCs. The experimental setup has been described in detail by Hao et al. (2009). Briefly, the system consists of a plant enclosure (fluorinated ethylene propylene (FEP) bag), a reaction chamber (made also of FEP film with a volume of $6 \mathrm{~m}^{3}$ ), and gas and particle measurement systems that are described in greater detail below. All branches with green needles on a 10 -yr-old Scots pine seedling were enclosed in an FEP bag, which was sealed on the stem bark. Plant-emitted VOCs were transported by purified and dried air into the separate reaction chamber in order to achieve the desired concentration of VOCs. To simulate herbivore attack on tree bark and to activate the chemical defence of seedlings, thereby enhancing VOC emissions, $1 \mathrm{~cm}$ long and $1 \mathrm{~mm}$ deep cuts were made on the base of the main stem by a knife.

Table 1 summarizes the experiments conducted in this research. The experiments are the same described in Virtanen et al. (2010). In experiment (\#1) ozone-initiated chemistry was explored, whereas in experiment (\#2) tetramethylethylene (TME) was added to the chamber to produce additional hydroxyl radicals $(\mathrm{OH})$ and increase the $\mathrm{OH}: \mathrm{O}_{3}$ ratio (i.e., 
oxidation conditions) in the reaction chamber (Lambe et al., 2007). In experiment (\#2) $1 \mathrm{ppm}$ of $\mathrm{SO}_{2}$ in nitrogen was also added to the chamber. After injecting the plant-derived VOCs, $700 \mathrm{ppb}$ of ozone generated by a UV lamp $\mathrm{O}_{3}$ generator was added to the chamber at a flow rate of $40 \mathrm{lpm}$ for approximately $8 \mathrm{~min}$. In all experiments, the temperature ( $T$ ) was $22 \pm 1{ }^{\circ} \mathrm{C}$ and relative humidity (RH) was controlled in the range of $30 \pm 5 \%$ (measured with Vaisala Humidity and Temperature Probe HMP50). Ozone (DASIBI 1008-RS $\mathrm{O}_{3}$ analyzers, Dasibi Environmental Corporation), $\mathrm{NO}_{\mathrm{x}}(\mathrm{AC}$ $30 \mathrm{M} \mathrm{NO}_{\mathrm{x}}$ analyzer Environment s.a.), $\mathrm{SO}_{2}\left(\mathrm{AF} 21 \mathrm{M} \mathrm{SO}_{2}\right.$ analyzer Environment s.a.) and VOC concentrations were measured inside the chamber during experiments. VOC samples were collected on Tenax-TA adsorbent and the samples were analyzed by gas chromatography-mass spectrometry (Vuorinen et al., 2004). The initial VOC concentrations inside the chamber before ozone addition were $18.8 \mathrm{ppb}$ and $107.6 \mathrm{ppb}$ for the ozone $\mathrm{O}_{3}$ (exp. \#1) and $\mathrm{OH}+\mathrm{SO}_{2}$ (exp. \#2) experiments, respectively. To increase aerosol mass loading in the experiment (\#1), two extra ozone injections were made at two hours after the first ozone addition.

The particle size distributions were measured by two scanning mobility particle sizers (SMPS) comprised of a Differential Mobility Analyzer (DMA; model 3081, TSI, Inc.) coupled to a condensation particle counter (CPC; model 3022, TSI, Inc.) and a nano DMA (model 3085, TSI, Inc.) coupled to a ultrafine CPC (model 3027, TSI, Inc.) with mobility diameter ranges of $10-700 \mathrm{~nm}$ and $3-60 \mathrm{~nm}$, respectively. Furthermore, chemical composition and mass size distributions of aerosol particles formed during the experiments were measured with a quadrupole-based Aerosol Mass Spectrometer (AMS, Aerodyne Inc.). The average density of particles was determined by comparing the SMPS volume and AMS mass size distributions (De Carlo et al., 2004).

The size distributions and bounce behaviour of particles, which are related to particle physical phase state, were determined with an electrical low pressure impactor (ELPI). In ELPI, particles are charged by a unipolar corona charger and after the charger, the particles enter a twelve stage cascade impactor (Keskinen et al., 1992), where the particles are classified according to their aerodynamic size, depending on both the physical size and the density of the particle. In a conventional ELPI set-up, the cut size of the lowest stage is approximately $30 \mathrm{~nm}$, however for these investigations the ELPI was equipped with an additional impactor stage with a cut-off size of $17 \mathrm{~nm}$. In addition, a back-up filter was used to measure particles smaller than the lowest impactor cut-off size.

\subsection{Particle bounce analysis}

In the normal operation of a cascade impactor, particle bounce perturbs the measurement as larger particles are transferred to lower stages following bounce thus biasing the inferred size distribution towards smaller sizes. When par- ticle bounce occurs in an ELPI, a significant excess current is measured in the lowest impactor stages resulting from the charges carried by the bounced particles.

Hence, particle bounce can be quantified by analyzing the difference in bounce-affected measured currents with ideal non-affected currents. To calculate the ideal currents the measured SMPS number distribution as a function of particle diameter, $n_{\text {SMPS }}\left(d_{p}\right)$, is converted to ELPI current response $i^{\text {id }}\left(d_{p}\right)$ by first multiplying the measured SMPS distribution by the ELPI charger efficiency curve, $E_{\mathrm{ch}}\left(d_{p}\right)$ (Ristimäki et al., 2002)

$i^{\mathrm{id}}\left(d_{p}\right)=n_{\mathrm{SMPS}}\left(d_{p}\right) E_{\mathrm{ch}}\left(d_{p}\right)$

Next, the resulting current distribution $i^{\text {id }}$ is passed through the ELPI impactor kernel functions $\mathrm{k}_{j}$ to mimic the particle collection within the impactor (Ristimäki et al., 2002). The kernel functions are carefully calibrated for chosen impactor units and substrate types. The current in the $\mathrm{j} t h$ impactor stage can be calculated from the following equation:

$I_{j}^{\mathrm{id}}=\int_{0}^{\infty} k_{j}\left(d_{p}, \rho\right) i^{\mathrm{id}}\left(d_{p}\right) d d_{p}$

Such calculations result in idealized ELPI currents. In the above calculations, the average particle density $(\rho)$ is required. For pine derived SOA particles measured in the smog chamber we use densities obtained from AMS - SMPS measurements (density value of $1.1 \mathrm{~g} \mathrm{~cm}^{-3}$ ). Note that the particle density was determined for particle diameters larger than $100 \mathrm{~nm}$ due to low mass loadings in the chamber and the low particle transmission efficiency of the AMS for particles smaller than $40 \mathrm{~nm}$. In the following section we shall explore relationship between particle bounce observations and density for particles smaller than $100 \mathrm{~nm}$ in diameter.

When the measured and ideal currents are compared, the fraction of excess current in the back-up filter can be estimated. This fraction is called the bounce factor (Virtanen et al., 2010). In the measurements reported by Virtanen et al. (2010), the bounce factor was determined reliably only for particles having GMD larger than $30 \mathrm{~nm}$. This was due to the fact that the lowest cut size of the impactor set-up used in atmospheric measurements was $30 \mathrm{~nm}$. If the ELPI is equipped with additional impactor stage having cut-size $17 \mathrm{~nm}$ (YliOjanperä et al., 2010), it is possible to extend the bounce characteristic investigations down to $17 \mathrm{~nm}$ according to (see also Fig. 1)

bounce factor $\equiv \frac{I_{\text {filter }}-I_{\text {filter }}^{\text {id }}}{\sum I_{\text {impactor stages } \geq 17 \mathrm{~nm}}^{\text {id }}}$,

where $I_{\text {filter }}$ is the current measured in back-up filter, $I_{\text {filter }}^{\text {id }}$ is the simulated ideal current in back up filter, and $\sum I_{\text {impactor stages } \geq 17 \mathrm{~nm}}^{\text {id }}$ is the sum of the ideal currents calculated from the impactor stages (excluding the back-up filter). 


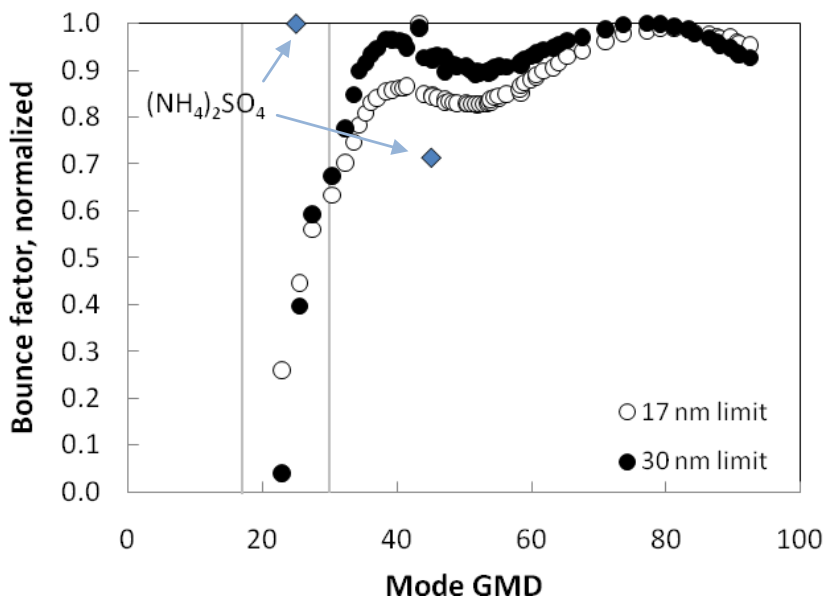

Fig. 1. Comparison of normalized bounce factors for measurements having $17 \mathrm{~nm}$ (open circles) and $30 \mathrm{~nm}$ (black dots) size limitations. In addition, reference measurements by ammonium sulphate particles are shown (blue diamonds).

Here the cut size of the last impactor stage is $17 \mathrm{~nm}$. We would like to point out that the bounce factor defined by Eq. (3) does not depend only on particle bounce properties but also on the charge transfer properties of the particles.

In the following section, we present the results calculated by the Eq. (3), and compare them to the results published in Virtanen et al. (2010) where the bounce factors were calculated by utilizing the same data but using the $30 \mathrm{~nm}$ size limitations.

\section{Results and discussion}

For comparison, the normalized bounce factors for 17 and $30 \mathrm{~nm}$ size limits are shown in Fig. 1 for particles produced by the $\mathrm{OH}$ dominated oxidation of pine emitted VOCs (in presence of added $\mathrm{SO}_{2}$ in the chamber). In Fig. 1, the bounce factors are calculated using the same data with two different size limitations, The results shown in Fig. 1 are calculated using particle density of $1.1 \mathrm{~g} \mathrm{~cm}^{-3}$ derived from the AMSSMPS measurements and they are shown as a function geometric mean mobility diameter (GMD) of SMPS size distributions. It should be noted, that the absolute value of bounce factors for size limits $17 \mathrm{~nm}$ and $30 \mathrm{~nm}$ differs because in the $30 \mathrm{~nm}$ case, the bounce factor is calculated according to the equation presented in Virtanen et al. (2010) instead of Eq. (3). The size limits of $17 \mathrm{~nm}$ and $30 \mathrm{~nm}$ are marked with grey vertical lines in the figure. As can be seen, the particle bounce factor clearly decreases in size range below $30 \mathrm{~nm}$.

The particle bounce data can be used to constrain the density of sub-30 nm diameter particles, for which little experimental data is available (Kannosto et al., 2008). In Fig. 2 we show the calculated bounce factor for data obtained with the $17 \mathrm{~nm}$ diameter size limit using density values varying from $0.8 \mathrm{~g} \mathrm{~cm}^{-3}$ to $2 \mathrm{~g} \mathrm{~cm}^{-3}$. The results indicate that in spite of possible uncertainties in the density, the bounce of the sub $30 \mathrm{~nm}$ particles clearly decreases with decreasing particle size. In addition, the bounce factor for particles $>40 \mathrm{~nm}$ is insensitive to the chosen density.

In the upper right corner of Fig. $2 a$ and $b$, the results of the details in bounce factor values for the smallest particle sizes are shown. The zero value for bounce factor is marked with dashed line in the figure. As can be seen, the bounce factor gets clearly negative values when low density values are used in calculations. Underestimating the density in the calculations results in unrealistically high simulated current values in the back up filter compared to the measured currents (i.e., unrealistic high values of $I_{\text {filter }}^{\text {id }}$ in Eq. 3), thus the numerator in Eq. (3) gets negative values. The closer the investigated size is to the cut size of lowest impactor stage (in this case $17 \mathrm{~nm}$ ) the more sensitive the calculated bounce factor is for the chosen density values. The estimated maximum uncertainty in the calculated bounce factor is ca. $10 \%$ including the noise in current measurement and the uncertainty in current simulations (but excluding the effect of the density values used in calculations which is shown in Fig. 2a and $b$ ). It is clear that for all used density values the changes in bounce factor in sub $30 \mathrm{~nm}$ size range in Fig. $2 \mathrm{a}$ and b are significant compared to the uncertainty in the bounce factor calculations.

In the case of particles formed by ozonolysis of pine derived VOC in the absence of $\mathrm{SO}_{2}$ (henceforth referred to as the " $\mathrm{O}_{3}$ case"), the bounce factor achieved positive values for the smallest measured mobility diameter $(18 \mathrm{~nm})$ when the density used in calculations are greater than $1.3 \mathrm{~g} \mathrm{~cm}^{-3}$ (Fig. 2a). In the case of $\mathrm{OH}$ initiated oxidation in the presence of $\mathrm{SO}_{2}$ (referred to as the "OH+SO${ }_{2}$ case"), the corresponding density value is $1.6 \mathrm{~g} \mathrm{~cm}^{-3}$ (Fig. 2b). This indicates that in the experiments with $\mathrm{SO}_{2}\left(\mathrm{OH}+\mathrm{SO}_{2}\right.$ case $)$, the density of the smallest particles is higher than in the absence of $\mathrm{SO}_{2}$ $\left(\mathrm{O}_{3}\right.$ case). In Fig. 4a the ratio of $\mathrm{SO}_{4}^{2-}$ to organics measured by the AMS is shown for $\mathrm{OH}+\mathrm{SO}_{2}$ case. It can be seen that smaller particles contained higher amount of $\mathrm{SO}_{4}^{2-}$ than larger particles. On the other hand, particles formed through ozonolysis in absence of $\mathrm{SO}_{2}$ contained no $\mathrm{SO}_{4}^{2-}$. Densities of inorganic compounds containing $\mathrm{SO}_{4}^{2-}$ are typically higher compared to organic compounds, e.g., $1.84 \mathrm{~g} \mathrm{~cm}^{-3}$ for sulphuric acid and ca. $1.77 \mathrm{~g} \mathrm{~cm}^{-3}$ for ammonium sulphate (Lide, 1996). This can explain the differences in densities of the smallest particles in these two cases. When the density values analyzed for larger particles $(50-100 \mathrm{~nm})$ from AMS and SMPS distributions shown in Table 1, no clear differences are observed. As Fig. 4a shows, at these larger sizes the ratio of $\mathrm{SO}_{4}^{2-}$ to organic decreases and particles become more similar to pure SOA.

The higher density values needed to gain the positive bounce factor (calculated from Eq. 3) for the $\mathrm{OH}+\mathrm{SO}_{2}$ case could be explained also by the lower bounced fraction of 

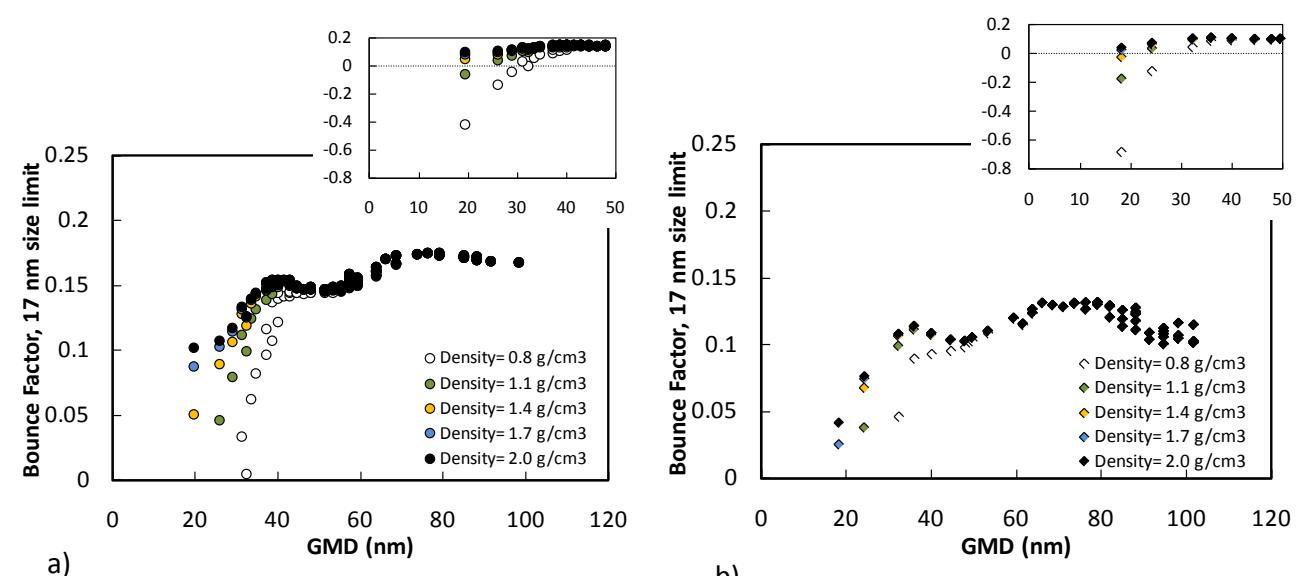

b)

Fig. 2. Calculated bounce factors for the $17 \mathrm{~nm}$ size limit measured for (a) $\mathrm{O}_{3}$ initiated oxidation in absence of $\mathrm{SO}_{2}$ and (b) $\mathrm{OH}$ dominated oxidation in presence of $\mathrm{SO}_{2}$. Density values varying from $0.8 \mathrm{~g} \mathrm{~cm}^{-3}$ to $2 \mathrm{~g} \mathrm{~cm}^{-3}$ were used in calculations. Insets in the upper right corners of (a) and (b) show details in bounce factor values for the smallest particles.

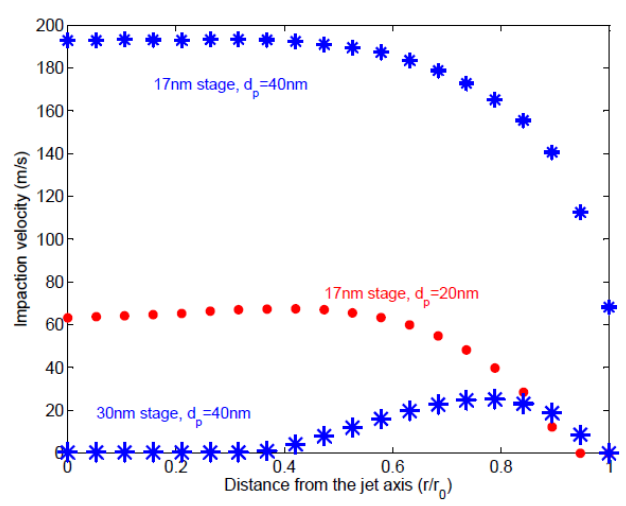

a)

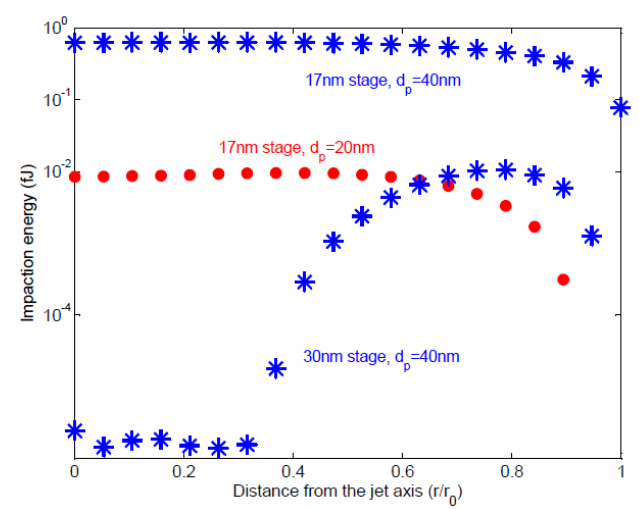

b)

Fig. 3. (a) Calculated impaction velocities and (b) impaction energies for the $20 \mathrm{~nm}$ particles impacting for the first time on the stage having $17 \mathrm{~nm}$ cut size (red dots) and $40 \mathrm{~nm}$ particles (blue stars) impacting on the $30 \mathrm{~nm}$ stage and $17 \mathrm{~nm}$ stage.

these particles (i.e., the lower measured current value in the filter stage $\left(I_{\text {filter }}\right)$ in Eq. 3 ) when compared to $\mathrm{O}_{3}$ case. In fact, when the bounce factors in Fig. 2a and $b$ are compared, it can be seen that the overall bounce factor for $\mathrm{OH}+\mathrm{SO}_{2}$ case is lower than for the $\mathrm{O}_{3}$. According to our earlier work (Virtanen et al., 2010) the bounce factor measured for ammonium sulphate particles is clearly lower than for amorphous polystyrene or SOA particles. This could be due to the difference in elastic properties of crystalline and amorphous materials or in charge transfer characteristics of these materials. One conclusion that one may draw from our observations that the differences in bounce behaviour of the smallest (around $20 \mathrm{~nm}$ ) particles in these two investigated cases are related to the $\mathrm{SO}_{4}^{2-}$ concentration in particles. The higher $\mathrm{SO}_{4}^{2-}$ fraction in smallest particles can result in higher density value of the particles or the lower bounce probability of the particles (or both of these). The effect of these differences can be seen in calculated bounce factors. The decrease of the $\mathrm{SO}_{4}^{2-}$ fraction in particles in $\mathrm{OH}+\mathrm{SO}_{2}$ case (Fig. 4a) with increasing particle size indicates also that the sulphate compounds play a key role in initial particle formation and the organics participate strongly on particle growth.

According to the results presented here, particle bounce clearly decreases with decreasing particle size. The decreasing bounce can be caused by two reasons. Firstly the decreasing bounce can be caused by the differences in composition and phase of larger (GMD $>30 \mathrm{~nm}$ ) and smaller (GMD $17-30 \mathrm{~nm}$ ) particles. In Fig. $4 \mathrm{a}$ and $\mathrm{b}$ the ratio of mass of m44 to mass of total organics analyzed from AMS data, which is a measure of the oxidation state of the particulate organics, is shown as a function of the GMD of number distribution for the $\mathrm{O}_{3}$ and $\mathrm{OH}+\mathrm{SO}_{2}$ experiments, respectively. It should be noted that the AMS composition data shown in Fig. 4 is presented as a function of GMD of 

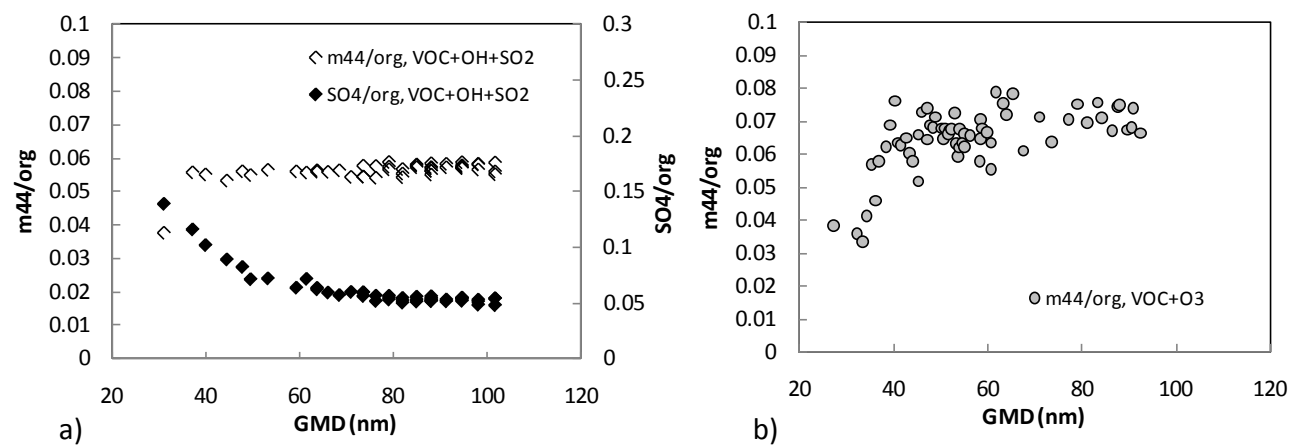

Fig. 4. $m 44 /$ total organics ratio of particles derived from (a) $\mathrm{OH}$ initiated oxidation of the pine emitted $\mathrm{VOCs}$, in the presence of $\mathrm{SO}_{2}$, and (b) ozonolysis of the pine-emitted VOCs.

number distribution measured by SMPS. In the $\mathrm{O}_{3}$ case, no $\mathrm{SO}_{4}^{2-}$ was detected in the AMS signal, as can be expected, but the particle oxidation degree of the smallest particles, as represented by the fraction of the $\mathrm{m} / \mathrm{z} 44$ fragment of the total organic mass concentration, is clearly lower than of the larger particles (Fig. 4b). A decreasing trend of $f 44$ with decreasing particle size can be seen in Fig. 4b indicating strong possibility of similar trend also in the sub $30 \mathrm{~nm}$ size range. Hence we can assume that the fresher sub $30 \mathrm{~nm}$ particles are less oxidized than the larger particles. As a matter of fact, the lower oxidation degree of the smallest particles might be related to the "less solid" nature of the particles: it is known that the oligomers or other organic compounds with high molar mass are more prone to glass formation than smaller molecules (Zobrist et al., 2008). Hydrogen bonding between oxygenated compounds and functional groups may also favor the formation of solid phases (Mikhailov et al., 2009). According to Fig. 2, the fresher particles having GMD of $18 \mathrm{~nm}$ have clearly lower bounce factor than more aged particles having GMD of $30 \mathrm{~nm}$. The time difference between these two measurements was approximately 15 minutes and the GMD $30 \mathrm{~nm}$ was measured approximately $25 \mathrm{~min}$ after the first particles were detected in the chamber. Thus, in these experimental conditions, we can make a rough approximation according to which the solidification takes place 10-25 min after the beginning of the nucleation process. The potential influence of oxidation and the age on the phase state of organic aerosol particles should be explored in future studies.

In the $\mathrm{OH}+\mathrm{SO}_{2}$ case, the measured fraction of particulate $\mathrm{SO}_{4}^{2-}$ increases with decreasing particles size but no clear changes in particle oxidation degree (f44) can be observed (Fig. 4a). As mentioned above, the bounce factor for $\mathrm{OH}+\mathrm{SO}_{2}$ case particles containing fraction of $\mathrm{SO}_{4}^{2-}$ is generally lower than bounce factor for $\mathrm{O}_{3}$ case (no $\mathrm{SO}_{4}^{2-}$ in particles). According to our earlier laboratory experiments (Virtanen et al., 2010) the bounce factor measured for ammonium sulphate particles is clearly lower than for amorphous polystyrene or SOA particles. This could be due to the differ- ence in elastic properties of crystalline and amorphous materials or in charge transfer characteristics of these materials. Hence the increasing fraction of $\mathrm{SO}_{4}^{2-}$ in smallest particles might also result in lowering bounce factor.

Secondly, it is important to note that with decreasing particle size the velocity needed for bounce to occur increases, since the required velocity is inversely proportional to particle size (Dahneke et al., 1971). On the other hand, 17$30 \mathrm{~nm}$ particles impact on the lowest impactor stage where the impactor jet velocities are generally higher than the jet velocities in the upper stage where, e.g., the $40 \mathrm{~nm}$ particle impacts for the first time. In addition, the contact velocities of particles impacting onto specific impactor stage depend on particle size: particles clearly larger than the cut point of the impaction stage have higher velocities than particles having size close to the cut point. We estimated the impaction velocities for $20 \mathrm{~nm}$ particles impacting the first time on the lowest impactor stage (having cut size $17 \mathrm{~nm}$ ) and $40 \mathrm{~nm}$ particles impacting the first time on the upper stage (having cut size of $30 \mathrm{~nm}$ ) by using the modeling method presented by Arffman et al. (2011). As can be seen in Fig. 3a, where the impaction velocities of the particles are presented as a function of the radial distance from the center of the jet, the impaction velocities for $20 \mathrm{~nm}$ particles in the lowest impactor stage are higher on the average than impaction velocities of $40 \mathrm{~nm}$ particles on the upper stage. Impaction velocities of the $40 \mathrm{~nm}$ particles are higher at the edges of the jet, because the slip correction factor increases rapidly towards edges of the jet as discussed by Arffman et al. (2011). Most of the particles flow through the center parts of the impactor jet where the impaction velocities of the $20 \mathrm{~nm}$ particles are much higher than the impaction velocities of $40 \mathrm{~nm}$ particles at the upper stage. In addition, Fig. 3a shows the impaction velocity of $40 \mathrm{~nm}$ particles bouncing from the upper stage to the lowest stage. The impaction velocity increases as $40 \mathrm{~nm}$ particles travel from upper stage to the lowest stage resulting in higher bounce probability. We also calculated the kinetic energy of the particles by assuming density $1 \mathrm{~g} \mathrm{~cm}^{-3}$. As can be seen in Fig. 3b, the kinetic energy of $20 \mathrm{~nm}$ particles at the lowest 
stage (cut size $17 \mathrm{~nm}$ ) is higher than the kinetic energy of the $40 \mathrm{~nm}$ particles impacting the upper stage (cut size $30 \mathrm{~nm}$ ). These results indicate that the decreasing particle size does not explain the observed decrease in bounce factor in the sub $40 \mathrm{~nm}$ size range.

To further clarify the effect of particle size on bounce, reference measurements using solid $25 \mathrm{~nm}$ and $45 \mathrm{~nm}$ ammonium sulphate particles were performed. The measured bounce for $25 \mathrm{~nm}$ particles was higher than for $45 \mathrm{~nm}$ particles resulting the ratio of 1.4 for the bounce $(25 \mathrm{~nm}) /$ bounce $(45 \mathrm{~nm})$. We assume that the increase of bounce factor with decreasing particle size is due to both the increase in impaction energy (ref. Fig. 3) and the changes in charge transfer properties with particle size. The corresponding ratio for pine derived SOA particles is 0.53 (for the $\mathrm{O}_{3}$ case) and 0.4 (for the $\mathrm{OH}+\mathrm{SO}_{2}$ case). Thus the behavior of bounce as a function of particle size is clearly different for solid ammonium sulphate particles and freshly nucleated pine derived SOA in sub $30 \mathrm{~nm}$ size range supporting the conclusion that the phase of newly formed sub $30 \mathrm{~nm}$ SOA particles is more liquid like than the phase of more aged larger particles.

\section{Conclusions}

The results reported here give information on the bounce characteristics (i.e., physical phase state) of smallest SOA particles produced by $\mathrm{O}_{3}$ initiated oxidation and by $\mathrm{OH}$ dominated oxidation with $\mathrm{SO}_{2}$ added in the chamber. Results strongly suggest that the decrease of bounce is caused by the differences in particle chemistry and their phase: the smaller (diameters between 17 and $30 \mathrm{~nm}$ ) particles having lower oxidation degree or containing higher amount of $\mathrm{SO}_{4}^{2-}$ bounced less than larger (diameters greater than $30 \mathrm{~nm}$ ) particles indicating different material characteristics in the case of fresher sub $30 \mathrm{~nm}$ size particles. The result might indicate that the initial nucleation process and growth of the newly formed particle is driven by mass transfer of molecules from gas phase to liquid phase. When particles are more aged, the solidification takes place and the partitioning process changes.

Acknowledgements. A. V. acknowledges the Maj and Tor Nessling Foundation for the financial support. J. J. acknowledges the support by the Academy of Finland (decision no. 110763, 111543, 131019, 218115 and Centre of Excellence Programme). J. S. acknowledges the financial support of the Saastamoinen foundation and the Office of Science (BER), US Department of Energy, grant DE-FG-02-05ER63997. The National Center for Atmospheric Research is sponsored by the US National Science Foundation.

Edited by: I. Riipinen

\section{References}

Arffman, A., Marjamäki, M., and Keskinen, J.: Simulation of low pressure impactor collection efficiency curves, J. Aerosol Sci., 42, 329-340, 2011.

Cappa, C. D. and Wilson, K. R.: Evolution of organic aerosol mass spectra upon heating: implications for OA phase and partitioning behavior, Atmos. Chem. Phys., 11, 1895-1911, doi:10.5194/acp11-1895-2011, 2011.

Chang M., Kim, S., and Sioutas, C.: Experimental studies on particle impaction and bounce effects of substrate design and materials, Atmos. Environ., 33, 2313-2322, 1999.

Claeys M., Graham, B., Vas, G., Wang, W., Vermeylen, R., Pashynska, V., Cafmeyer, J., Guyon, P., Andreae, M. O., Artaxo, P., and Maenhaut, W.: Formation of secondary organic aerosols through photooxidation of isoprene, Science, 303, 1173-1176, 2004.

Dahneke, B.: Capture of aerosol particles by surfaces, J. Coll. Interface Sci. 37, 342-347, 1971.

De Carlo, P. F., Slowik, J. G., Worsnop, D. R., Davidovits, P., and Jimenez, J. L.: Particle morphology and density characterization by combined mobility and aerodynamic diameter measurements. Part 1: Theory, Aerosol. Sci. Technol., 38, 1185-1205, 2004.

Hallquist, M., Wenger, J. C., Baltensperger, U., Rudich, Y., Simpson, D., Claeys, M., Dommen, J., Donahue, N. M., George, C., Goldstein, A. H., Hamilton, J. F., Herrmann, H., Hoffmann, T., Iinuma, Y., Jang, M., Jenkin, M. E., Jimenez, J. L., Kiendler-Scharr, A., Maenhaut, W., McFiggans, G., Mentel, Th. F., Monod, A., Prévôt, A. S. H., Seinfeld, J. H., Surratt, J. D., Szmigielski, R., and Wildt, J.: The formation, properties and impact of secondary organic aerosol: current and emerging issues, Atmos. Chem. Phys., 9, 5155-5235, doi:10.5194/acp-95155-2009, 2009.

Hao, L. Q., Yli-Pirilä, P., Tiitta, P., Romakkaniemi, S., Vaattovaara, P., Kajos, M. K., Rinne, J., Heijari, J., Kortelainen, A., Miettinen, P., Kroll, J. H., Holopainen, J. K., Smith, J. N., Joutsensaari, J., Kulmala, M., Worsnop, D. R., and Laaksonen, A.: New particle formation from the oxidation of direct emissions of pine seedlings, Atmos. Chem. Phys., 9, 8121-8137, doi:10.5194/acp9-8121-2009, 2009.

Jimenez., J. L., Canagaratna, M. R., Donahue, N. M., Prevot, A. S. H., Zhang, Q., Kroll, J. H., DeCarlo, P. F., Allan, J. D., Coe, H., Ng, N. L., Aikene, A. C., Docherty, K.S., Ulbrich, I.M., Grieshop, A. P., Robinson, A. L., Duplissy, J., Smith, J. D., Wilson, K. R., Lanz, V. A., Hueglin, C., Sun, Y. L., Tian, J., Laaksonen, A., Raatikainen, T., Rautiainen, J., Vaattovaara, P., Ehn, M., Kulmala, M., Tomlinson, J. M., Collins, D. R., Cubison, M. J., Dunlea, E. J., Huffman, J. A., Onasch, T. B., Alfarra, M. R., Williams, P. I., Bower, K., Kondo, Y., Schneider, J., Drewnick, F., Borrmann, S., Weimer, S., Demerjian, K., Salcedo, D., Cottrell, L., Griffin, R., Takami, A., Miyoshi, T., Hatakeyama, S., Shimono, A., Sun, J. Y., Zhang, Y. M., Dzepina, K., Kimmel, J. R., Sueper, D., Jayne, J. T., Herndon, S. C., Trimborn, A. M., Williams, L. R., Wood, E. C., Middlebrook, A. M., Kolb, C. E., Baltsenberger, U., and Worsnop, D. R.: Evolution of Organic Aerosols in the Atmosphere, Science, 326, 1525-1529, 2009.

Laaksonen, A., Kulmala, M., O’Dowd, C. D., Joutsensaari, J., Vaattovaara, P., Mikkonen, S., Lehtinen, K. E. J., Sogacheva, L., Dal Maso, M., Aalto, P., Petäjä, T., Sogachev, A., Yoon, Y. J., Lihavainen, H., Nilsson, D., Facchini, M. C., Cavalli, F., Fuzzi, S., Hoffmann, T., Arnold, F., Hanke, M., Sellegri, K., Umann, B., 
Junkermann, W., Coe, H., Allan, J. D., Alfarra, M. R., Worsnop, D. R., Riekkola, M.-L., Hyötyläinen, T., and Viisanen, Y.: The role of VOC oxidation products in continental new particle formation, Atmos. Chem. Phys., 8, 2657-2665, doi:10.5194/acp-82657-2008, 2008.

Lide, D. R. (Ed.): CRC handbook of chemistry and physics (77th ed.), Boco Raton, FL, USA, CRC Press, 1996.

Kanakidou, M., Seinfeld, J. H., Pandis, S. N., Barnes, I., Dentener, F. J., Facchini, M. C., Van Dingenen, R., Ervens, B., Nenes, A., Nielsen, C. J., Swietlicki, E., Putaud, J. P., Balkanski, Y., Fuzzi, S., Horth, J., Moortgat, G. K., Winterhalter, R., Myhre, C. E. L., Tsigaridis, K., Vignati, E., Stephanou, E. G., and Wilson, J.: Organic aerosol and global climate modelling: a review, Atmos. Chem. Phys., 5, 1053-1123, doi:10.5194/acp-5-1053-2005, 2005.

Kannosto, J., Virtanen, A., Lemmetty, M., Mäkelä, J. M., Keskinen, J., Junninen, H., Hussein, T., Aalto, P. P., and Kulmala, M.: Mode resolved density of atmospheric aerosol particles, Atmos. Chem. Phys., 8, 5327-5337, doi:10.5194/acp-8-5327-2008, 2008.

Kulmala, M., Vehkamäki, H., Petäjä, T., Dal Maso, M., Lauri, A., Kerminen, V.-M., Bilmili, W., and McMurry, P.: Formation and growth rates of ultrafine atmospheric aerosol particles: a review of observations, J. Aerosol Sci., 35, 143-176, 2004.

Laaksonen, A., Hamed, A., Joutsensaari, J., Hiltunen, L., Cavalli, F., Junkermann, W., Asmi, A., Fuzzi, S., and Facchini, M. C.: Cloud condensation nuclei production from nucleation events at a highly polluted region, Geophys. Res. Lett., 32, L06812, doi:10.1029/2004GL022092, 2005.

Lambe, A. T., Zhang, J. Y., Sage, A. M., and Donahue, N. M.: Controlled $\mathrm{OH}$ radical production via ozone-alkene reactions for use in aerosol aging studies, Environ. Sci. Technol., 41, 23572363, 2007.

Martin, S.: Phase transitions of aqueous atmospheric particles, Chem. Rev., 100, 3403-3453, 2000.

Mikhailov, E., Vlasenko, S., Martin, S. T., Koop, T., and Pöschl, U.: Amorphous and crystalline aerosol particles interacting with water vapor: conceptual framework and experimental evidence for restructuring, phase transitions and kinetic limitations, Atmos. Chem. Phys., 9, 9491-9522, doi:10.5194/acp-9-9491-2009, 2009.

Murray, B. J.: Inhibition of ice crystallisation in highly viscous aqueous organic acid droplets, Atmos. Chem. Phys., 8, 54235433, doi:10.5194/acp-8-5423-2008, 2008.
Odum, J. R., Hoffmann, T., Bowman, F., Collins, D., Flagan, R. C., and Seinfeld, J. H.: Gas/particle partitioning and secondary organic aerosol yields, Environ. Sci. Technol., 30, 2580-2585, 1996.

Pankow, J. F.: An absorption model of the gas/aerosol partitioning involved in the formation of secondary organic aerosol, Atmos. Environ., 28, 189-193, 1994.

Ristimäki, J., Virtanen, A., Rostedt, A., and Keskinen, J.: On-line measurement of size distribution and effective density of submicron aerosol particles, J. Aerosol Sci. 33, 1541-1557, 2002.

Rogers, L. N. and Reed, J.: The adhesion of particles indergoing elastic-plastic impact with a surface, J. Phys. D, 17, 677-689, 1984.

Spracklen, D., Carslaw, K., Kulmala, M., Kerminen, V.-M., Mann, G., and Sihto, S.-L.: The contribution of boundary layer nucleation events to total particle concentrations on regional and global scales, Atmos. Chem. Phys., 6, 5631-5648, doi:10.5194/acp-6-5631-2006, 2006.

Stein, S. W., Turpin, J. B., Cai, X., Huang, P. F., and McMurry, P. H.: Measurements of relative humidity dependent bounce and density for atmospheric particles using DMA-impactor technique, Atmos. Environ., 28, 1739-1746, 1994.

Tunved, P., Hansson, H.-C., Kerminen, V.-M., Ström, J., Dal Maso, M., Lihavainen, H., Viisanen, Y., Aalto, P. P., Komppula, M., and Kulmala, M.: High Natural Aerosol Loading over Boreal Forests, Science, 312, 261-263, 2006.

Virtanen, A., Joutsensaari, J., Koop, T., Kannosto, J., Yli-Pirilä, P., Leskinen, J., Mäkelä, J. M., Holopainen, J. K., Pöschl, U., Kulmala, M., Worsnop, D. R., and Laaksonen, A.: An amorphous solid state of biogenic secondary organic aerosol particles, Nature, 467, 824-827, 2010.

Vuorinen, T., Nerg, A. M., Ibrahim, M. A., Reddy, G. V. P., and Holopainen, J. K.: Emission of Plutella xylostella-induced compounds from cabbages grown at elevated $\mathrm{CO} 2$ and orientation behavior of the natural enemies, Plant Physiol., 135, 1984-1992, 2004.

Yli-Ojanperä, J., Kannosto, J., Marjamäki, M., and Keskinen, J.: Improving the Nanoparticle Resolution of the ELPI, Aerosol Air Qual. Res., 10, 360-366, 2010.

Zobrist, B., Marcolli, C., Pedernera, D. A., and Koop, T.: Do atmospheric aerosols form glasses?, Atmos. Chem. Phys., 8, 52215244, doi:10.5194/acp-8-5221-2008, 2008. 